\title{
Regulation of the Production and Catabolism of Plasma Low Density Lipoproteins in Hypertriglyceridemic Subjects

\author{
Effect of Weight Loss
}

Henry N. Ginsberg, Ngoc-Anh Le, and Joyce C. Gibson

Division of Arteriosclerosis and Metabolism, Department of Medicine, and Department of Biomathematical Science, Mount Sinai School of Medicine, New York, New York 10029

\begin{abstract}
In subjects with hypertriglyceridemia, plasma concentrations of low density lipoprotein (LDL) cholesterol are often normal or reduced. Perturbations that alter plasma very low density lipoprotein (VLDL) concentrations are associated with opposite changes in plasma LDL levels. To determine the mechanisms regulating plasma LDL levels, we used ${ }^{131}$ I-VLDL and ${ }^{125} \mathrm{I}$ LDL to measure the fractional catabolic rates (FCR), production rates (PR), and rates of interconversion of apoprotein $B$ (apo B) in VLDL, intermediate density lipoprotein, and LDL in six hypertriglyceridemic subjects pre- and post-weight reduction. $\left[2-{ }^{3} \mathbf{H}\right]$ glycerol was used to quantitate VLDL triglyceride PR. All data are presented as mean \pm SD. Percent ideal body weight fell from $132 \pm 17.9$ to $119 \pm 15.9 \%$ in the group, $P<0.05$. After weight loss, plasma VLDL triglyceride $(486.0 \pm 364.1$ vs. $191.3 \pm 65.4 \mathrm{mg} / \mathrm{dl}, P<0.05)$ and VLDL apo $B(32.2 \pm 12.0$ vs. $14.8 \pm 6.8 \mathrm{mg} / \mathrm{dl}, P<0.05)$ concentrations were reduced. VLDL triglyceride $P R$ also fell after weight reduction (56.6 \pm 39.0 vs. $28.6 \pm 23.1 \mathrm{mg} / \mathrm{kg}$ per $\mathrm{h}, P<0.05)$, as did VLDL apo $B$ PR $(47.9 \pm 41.4$ vs. $19.0 \pm 14.1 \mathrm{mg} / \mathrm{kg}$ per d, $P<0.05)$.
\end{abstract}

Pre-weight loss, plasma LDL cholesterol and apo B levels were low-normal or reduced $(64.0 \pm 12.6$ and $58.4 \pm 11.9 \mathrm{mg} / \mathrm{dl}$, respectively) despite normal or elevated LDL apo B PR $(17.4 \pm 7.2 \mathrm{mg} / \mathrm{kg}$ per $\mathrm{d})$. The reduced cholesterol and apo $B$ levels were associated with increased FCRs $\left(0.68 \pm 0.29 \mathrm{~d}^{-1}\right)$ and reduced cholesterol/protein ratios $(1.01 \pm 0.18)$ in $L D L$. The plasma levels of $L D L$ cholesterol and apo $B$ rose after weight reduction $(84.8 \pm 24.9, P<0.05$; and $69.5 \pm 14.3 \mathrm{mg} / \mathrm{dl}$, $P<0.05$, respectively, vs. base line). These increased concentrations resulted from a combination of events. First, the FCR for LDL apo $B$ fell in five of six subjects with a significant reduction for the group as a whole $\left(0.48 \pm 0.11 \mathrm{~d}^{-1}, P<0.05\right.$ vs. base line). Second, the cholesterol/protein ratio increased in all six subjects with a significantly greater mean after weight loss (1.25 $\pm 0.27, P<0.05$ vs. base line). In contrast, the $L D L$ apo $B$ PR fell or was essentially unchanged in the six subjects

This work was presented in preliminary abstract form at the National Meeting of the AFCR-ASCI-AAP, May 1982.

Dr. Ginsberg is an I. T. Hirschl Scientist. Address correspondence to Dr. Ginsberg, Mount Sinai School of Medicine, Annenberg 24-48, 1 Gustave L. Levy Place, New York, NY 10029.

Received for publication 11 October 1983 and in revised form 11 October 1984.

J. Clin. Invest.

(C) The American Society for Clinical Investigation, Inc.

$0021-9738 / 85 / 02 / 614 / 10 \$ 1.00$

Volume 75, February 1985, 614-623 after weight loss (mean, $14.4 \pm 2.8 \mathrm{mg} / \mathrm{kg}$ per d; NS vs. preweight loss). The changes in LDL catabolism and composition were associated with changes in the source of LDL apo $B$. Pre-weight loss, $73.3 \%$ of LDL was derived from VLDL, while 26.7\% was directly secreted into plasma. Post-weight reduction, VLDL-derived LDL fell to $\mathbf{4 6 . 8 \%}$ of total, while direct secretion accounted for $53.2 \%$ of LDL production. These changes were significant; $P<0.05$. Thus, all subjects had direct secretion of LDL apo B and the magnitude of this source of LDL seemed to be inversely related to the rate of VLDL triglyceride secretion. These results indicate that the regulation of plasma LDL levels in hypertriglyceridemic subjects is quite complex and that the rise in LDL levels after weight loss results from reductions in the fractional catabolism of this lipoprotein. The fall in the FCR is associated with changes in the source of LDL and in its composition.

\section{Introduction}

In humans, net cholesterol transport from the liver to the peripheral tissues seems to involve three plasma lipoprotein classes: very low density lipoproteins (VLDL; $d 1.006 \mathrm{~g} / \mathrm{ml})^{1}$, intermediate density lipoproteins (IDL; $d 1.006-1.019 \mathrm{~g} / \mathrm{ml}$ ), and low density lipoproteins (LDL; $d$ 1.019-1.063 g/ml). 60$70 \%$ of the total plasma cholesterol is found in the latter lipoprotein class in normolipidemic subjects. Several groups have studied the turnovers of these lipoproteins by using radiolabeled VLDL and following the radioactivity of the major structural protein, apoprotein B (apo B), in VLDL, IDL, and LDL. The results of these studies have suggested that VLDL enters the plasma from the liver and is converted to IDL and/or LDL as a result of intravascular catabolism (1-4). Furthermore, studies using both radiolabeled VLDL and LDL have suggested that in normal subjects, VLDL apo $B$ is essentially the sole source of $\operatorname{LDL}$ apo $B(5,6)$. In vitro studies using a variety of cultured cell systems have demonstrated that receptor-mediated binding and internalization of LDL play a significant role in the removal of these lipoproteins from plasma and the interstitial fluid (7). In vivo studies using native and modified LDL tracers (8-10) confirmed the importance of receptor-mediated catabolism of LDL.

Based on the above observations, it seems that the plasma concentration of LDL cholesterol would be regulated by the rate of production of VLDL (which in turn would regulate the production of $L D L$ ) and/or the fractional catabolic rate (FCR) of LDL $(8,11-13)$. Individuals with elevated plasma VLDL

1. Abbreviations used in this paper: apo, apoprotein; FCR, fractional catabolic rate; IDL, intermediate density lipoproteins; LDL, low density lipoproteins; PR, production rate; VLDL, very low density lipoproteins. 
levels have increased production of both VLDL triglyceride and VLDL apo $B(2-3,13-17)$. It might be assumed, therefore, that plasma LDL levels would also be elevated in these subjects. However, they frequently have normal or even reduced plasma LDL cholesterol concentrations even though total plasma cholesterol levels are increased $(18,19)$. Furthermore, when dietary $(20,21)$ or drug $(21,22)$ interventions reduce both VLDL production and plasma triglyceride levels, the concentration of plasma LDL cholesterol often increases. On the other hand, when high carbohydrate diets increase VLDL production, LDL concentrations fall (23).

These observations in hypertriglyceridemic subjects under base-line conditions, and when VLDL production has been altered, are inconsistent with a simple regulatory system linking VLDL production to plasma LDL concentrations. Reduced conversion of VLDL apo B to LDL in hypertriglyceridemic subjects compared with normals $(3,5)$ could explain the data in the former group in the base-line state. However, Janus et al. (6) reported similar degrees of conversion of VLDL apo B to LDL in normal and hypertriglyceridemic individuals. In the only study of VLDL apo B metabolism before and after a perturbation, we demonstrated that the reciprocal changes in VLDL and LDL concentrations resulting from a high carbohydrate diet were associated with a reduction in the percent of VLDL apo B converted to LDL (4). However, generation of LDL from sources other than VLDL and changes in the fractional catabolism of LDL could not be evaluated in that study. The possible importance of these factors is supported by data indicating both independent production $(14,24)$ and increased fractional catabolism $(11,13,25)$ of LDL in hypertriglyceridemic subjects in the base-line state. In the present study we have used $\left[{ }^{3} \mathrm{H}\right]$ glycerol, ${ }^{131} \mathrm{I}-\mathrm{VLDL}$, and ${ }^{125} \mathrm{I}-\mathrm{LDL}$ to simultaneously evaluate VLDL production, the conversion of VLDL to LDL, the sources of LDL, and the fractional catabolism of LDL before and after weight loss, a perturbation known to cause reciprocal changes in plasma VLDL and LDL concentrations. The results clearly demonstrate the complex nature of the regulation of LDL concentrations in subjects with hypertriglyceridemia.

\section{Methods}

Subjects. All subjects were males and were chosen because of the presence of hypertriglyceridemia and the absence of an elevated plasma
LDL cholesterol concentration in a random fasting blood sample. All subjects had, therefore, the Type IV phenotype while consuming ad lib. diets (26). The clinical characteristics of the group are depicted in Table I. The patients' ages ranged from 32 to $65 \mathrm{yr}$. Two of the hypertriglyceridemic subjects were within $20 \%$ of ideal body weight and four individuals were obese. There was a wide range of fasting plasma total triglyceride concentrations, while plasma total cholesterol levels were normal to slightly increased (27). Plasma high density lipoprotein cholesterol levels were uniformly reduced (27). None of the hypertriglyceridemic group had thyroid, renal, or hepatic dysfunction. Subject no. 2 had mild nonketotic diabetes mellitus treated with diet therapy. During the base-line study, his fasting plasma glucose concentrations were all $<150 \mathrm{mg} / \mathrm{dl}$ and his postprandial concentrations $<200 \mathrm{mg} / \mathrm{dl}$. He had no glucosuria. After weight reduction, fasting and postprandial glucose levels were $<120$ and $150 \mathrm{mg} / \mathrm{dl}$, respectively. He was asymptomatic during both study periods. Subjects 1,2 , and 6 were receiving beta-blocking agents and/or thiazide drugs for hypertension and/or ischemic heart disease. These agents were administered in the same dose through both study periods. No subject had received any hypolipidemic agents for at least 2 mo before the base-line study.

Although the group was heterogeneous and probably represented the phenotypic expression of several genotypes, there was no attempt to characterize those genotypes because of the absence of any specific genotypic markers for the common hypertriglyceridemias. Attempts were made to identify known, specific abnormalities associated with hyperlipoproteinemia. Levels of lipoprotein and hepatic triglyceride lipase in postheparin plasma were measured in all subjects and were within the normal range (data not shown). All of the subjects had normal levels of apo CII. None of the subjects had a ratio of cholesterol to triglyceride in VLDL that was $>0.35$ and none were homozygous for apo E2. As noted above, there was no evidence for secondary hyperlipoproteinemias except in subject no. 2. In this subject, however, the severity of the hypertriglyceridemia was disproportionate to the mild degree of his hyperglycemia.

All studies were carried out with the subjects as inpatients in the General Clinical Research Center at The Mount Sinai School of Medicine, New York. Informed consent was obtained before each study. Each subject underwent a turnover study (see below) in the base-line state. Body weights had been stable for at least $8 \mathrm{wk}$ before these studies. Post-weight reduction studies were carried out 3-6 mo after their base-line studies and after 4-10 wk of weight maintenance at their new reduced weight.

Protocol. After admission, subjects were given a solid food diet of $45 \%$ carbohydrate, $40 \%$ fat, and $15 \%$ protein with a polyunsaturated/ saturated fat ratio of 0.4 , and $150 \mathrm{mg}$ cholesterol per $1,000 \mathrm{kcal} / \mathrm{d}$. Diet stabilization occurred over a 5-10-d period. There was usually some reduction in plasma triglyceride levels during the initial days of the stabilization period. After stabilization, plasma was obtained after an overnight fast for isolation of VLDL and LDL. $4 \mathrm{~d}$ later, subjects

Table I. Subject Characteristics

\begin{tabular}{|c|c|c|c|c|c|c|c|c|}
\hline \multirow[b]{2}{*}{ Subjects } & \multirow[b]{2}{*}{ Age } & \multicolumn{2}{|c|}{ Actual weights } & \multicolumn{2}{|c|}{$\begin{array}{l}\text { Percent ideal } \\
\text { body weight }\end{array}$} & \multirow[b]{2}{*}{ Plasma cholesterol } & \multirow[b]{2}{*}{ Plasma triglycerides } & \multirow[b]{2}{*}{$\begin{array}{l}\text { High density } \\
\text { lipoprotein cholesterol }\end{array}$} \\
\hline & & A & B & A & B & & & \\
\hline & $y r$ & & & & & $m g / d l$ & $m g / d l$ & $m g / d l$ \\
\hline 1 & 56 & 89.0 & 81.0 & 139 & 127 & 179 & 409 & 25 \\
\hline 2 & 47 & 67.2 & 62.1 & 108 & 100 & 335 & 1,440 & 25 \\
\hline 3 & 45 & 85.3 & 74.3 & 118 & 104 & 200 & 371 & 22 \\
\hline 4 & 32 & 92.0 & 84.1 & 139 & 127 & 244 & 234 & 34 \\
\hline 5 & 65 & 107.3 & 96.8 & 159 & 142 & 258 & 965 & 21 \\
\hline 6 & 63 & 81.2 & 73.1 & 129 & 114 & 228 & 645 & 22 \\
\hline
\end{tabular}

* Based on the Metropolitan Life Insurance tables. A, baseline. B, post-weight reduction. Values were obtained at the time of identification as subjects for study. 
received $50 \mu \mathrm{Ci}$ of ${ }^{131} \mathrm{I}-\mathrm{VLDL}$ and $300 \mu \mathrm{Ci}$ of $\left[{ }^{3} \mathrm{H}\right]$ glycerol intravenously, and 18 blood samples were taken over the next $48 \mathrm{~h}$ (23). During this time period, the subjects consumed a liquid formula that consisted of $75 \%$ carbohydrate and $25 \%$ protein and provided $60 \%$ of their daily caloric intake (23). Diets identical or similar to this have been used by several other investigators $(3,6,13-17,28-29)$ to allow measurement of apo B turnover in the absence of exogenous triglyceride absorption and chylomicron transport. While this approach is certainly not optimal, it enables investigators to maintain steady-state VLDL triglyceride concentrations at the level present before the turnover study period, and allows the investigator to reasonably characterize the state of lipoprotein metabolism present during the preceding dietary period. $72 \mathrm{~h}$ after injection of VLDL, $25 \mu \mathrm{Ci}$ of ${ }^{125} \mathrm{I}$-LDL was administered intravenously and eight timed blood samples were obtained over the following $24 \mathrm{~h}$. The subjects returned to the original solid food diet on that day. Thereafter, daily fasting blood samples were obtained for 12-14 d. All subjects received $100 \mathrm{mg}$ of iodide as a saturated solution of potassium iodide twice daily throughout the study period.

Laboratory. VLDL were isolated at plasma density $(d, 1.006)$ by ultracentrifugation as previously described (23). LDL $(d, 1.025-1.060)$ was isolated by three sequential ultracentrifugational steps including a $60 \mathrm{Ti}$ rotor at $59,000 \mathrm{rpm}, d 1.025$; a $75 \mathrm{Ti}$ rotor at $65,000 \mathrm{rpm}, d$ 1.060 ; and a 40.3 rotor at $39,000 \mathrm{rpm}$, at $d 1.063$. Each ultracentrifugation was performed at $10^{\circ} \mathrm{C}$ for $20-24 \mathrm{~h}(8,30)$. All procedures were carried out using aseptic technique and sterilized equipment. The lipoproteins were iodinated by a modification (1) of the iodine monochloride method (31). The lipoproteins were then diluted in $0.15 \mathrm{M}$ $\mathrm{NaCl}$ and human serum albumin (final concentration, $5 \mathrm{~g} / \mathrm{dl}$ ) and passed through filters (Millipore Corp., Bedford, MA) (VLDL, 0.45 $\mu \mathrm{m}$; and LDL, $0.22 \mu \mathrm{m}$ ) before storage in sterile vials. [2- $\left.{ }^{3} \mathrm{H}\right]$ glycerol (New England Nuclear, Boston, MA) was diluted to a concentration of $300 \mu \mathrm{Ci} / \mathrm{ml}$ and passed through a filter $(0.22 \mu \mathrm{m}$; Millipore Corp.) before use.

VLDL, IDL, and LDL were isolated by sequential ultracentrifugation from the 18 plasma samples obtained during the $48 \mathrm{~h}$ after injection of ${ }^{131} \mathrm{I}-\mathrm{VLDL}$ and $\left[{ }^{3} \mathrm{H}\right]$ glycerol as previously described (4). The specific radioactivity of ${ }^{131} \mathrm{I}$-apo $\mathrm{B}$ in each of the three lipoprotein classes was determined using 1,1',3,3'-tetramethylurea to separate apo B from the other apoproteins present (32). Each specific activity determination was carried out in duplicate or triplicate directly upon the apo B pellet. The specific radioactivity of $\mathrm{VLDL}\left[{ }^{3} \mathrm{H}\right]$ triglyceride was determined by the method of Grundy et al. (28).

After separate injection of ${ }^{125} \mathrm{I}-\mathrm{LDL}$, LDL were isolated from plasma samples obtained during the next 2 wk by sequential ultracentrifugation at $d 1.020$ and then at $d 1.063$ in a 40.3 rotor at 39,000 $\mathrm{rpm}$ at $10^{\circ} \mathrm{C}$ for $24 \mathrm{~h}$ each. ${ }^{125} \mathrm{I}$-apo B-specific activity was then calculated using the protein concentration determined for each sample by the method of Lowry et al. (33) and the gamma radioactivity of that sample. Because apo B accounts for $>95 \%$ of the protein in LDL, this method results in specific radioactivities for LDL apo $B$ that are essentially identical to those obtained by isolation of apo B with 1,1',3,3'-tetramethylurea (32). Gamma and beta radioactivity were measured in scintillation counters (Packard Instruments Co., Downers Grove, IL).

Cholesterol and triglyceride concentrations were measured by specific enzymatic methods using an ABA-100 analyzer (Abbott Laboratories, Chicago, IL). Lipoprotein cholesterol levels were determined after ultracentrifugation according to Lipid Research Clinic methodology (34), except that dextran sulfate and $\mathrm{MnCl}_{2}$ were used to precipitate the lower density lipoproteins before measurement of high density lipoprotein cholesterol (35). This method results in HDL cholesterol concentrations that are $\sim 10 \%$ lower than those obtained using the Lipid Research Clinic method.

Sodium dodecyl sulfate gel electrophoresis of VLDL and LDL in $3.5 \%$ acrylamide gels was performed according to the method of Krishnaiah et al. (36). Agarose electrophoresis was carried out by the method of Noble (37).
Quantitation of apo B in VLDL, IDL, and LDL was carried out using electroimmunoassay (38) (subjects $1-4$ ) and radioimmunoassay (39) (subjects 5-6). Both assays used the same goat anti-human apo B antisera. Comparison of the two methods in our laboratory revealed that there was less than a $10 \%$ difference between values obtained from lipoprotein samples assayed by both procedures. Samples assayed by electroimmunoassay were first subjected to incubation with purified bovine milk lipoprotein lipase before measurement of apo B to unmask all antigenic sites. This step was unnecessary for radioimmunoassay of apo B.

Data analysis. Three separate multicompartmental models have been used to analyze the tracer data in the present study. The injection of $\left[{ }^{3} \mathrm{H}\right]$ glycerol resulted in the complex curve depicted in Fig. $1 \mathrm{~A}$. A five-pool model based on the radioactivity data for $\left[{ }^{3} \mathrm{H}\right] \mathrm{VLDL}$ triglyceride described by the curve was used to estimate the FCR of VLDL triglyceride (Fig. $1 B$ ). Comparison of this reduced model of VLDLtriglyceride kinetics and the more complete model reported by Zech et al. (29) has been published (40). Production rates of VLDL triglyceride were obtained by multiplying the FCR by the steady state plasma pool of this lipid during the 48-h turnover period.

The series of curves describing the specific radioactivity of apo B in VLDL, IDL, and LDL generated by the injection of ${ }^{131}$ I-VLDL are shown in Fig. $2 A$. The present data were analyzed using apo B specific radioactivity in the three lipoprotein fractions and a nonlinear regression
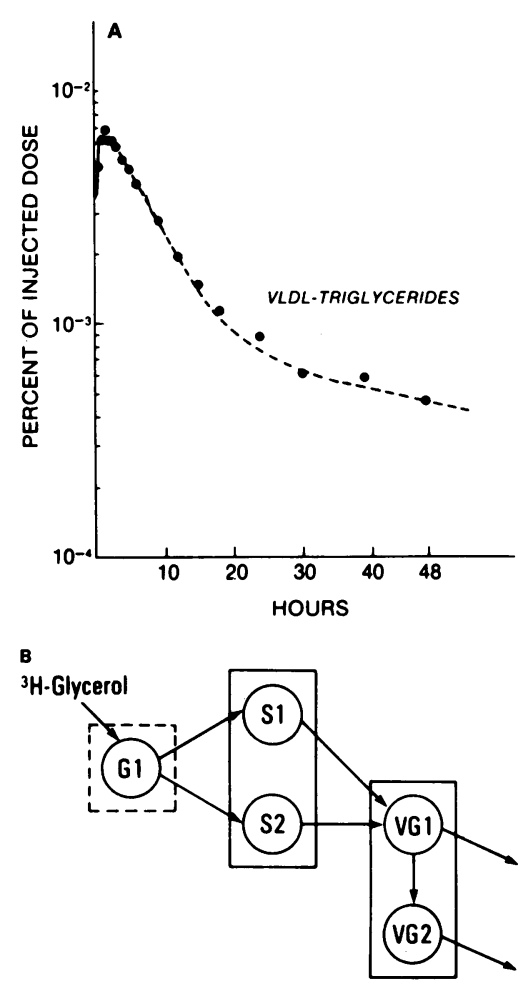

Figure $1 \mathrm{~A}$. Plasma VLDL $\left[{ }^{3} \mathrm{H}\right]$ triglyceride radioactivity curve, as percent of injected dose, after intravenous injection of $\left[2-{ }^{3} \mathrm{H}\right] \mathrm{glycerol}$. The curve consists of several components, including a biexponential decay after the maximum radioactivity is reached. $(B)$ Compartmental model describing the kinetics of VLDL triglyceride synthesis, secretion, and removal from plasma after injection of $\left[2-{ }^{3} \mathrm{H}\right] \mathrm{glycerol}$. The model includes a precursor pool for triglyceride synthesis (G1) that is derived from plasnia glycerol; fast (S1) and slow (S2) synthetic pools of triglyceride synthesis; and a two-pool system for plasma VLDL triglyceride catabolism. The latter system has a pool (VG1) that has a rapid fractional turnover and a pool (VG2) derived from VG1, that has a slower fractional turnover. 


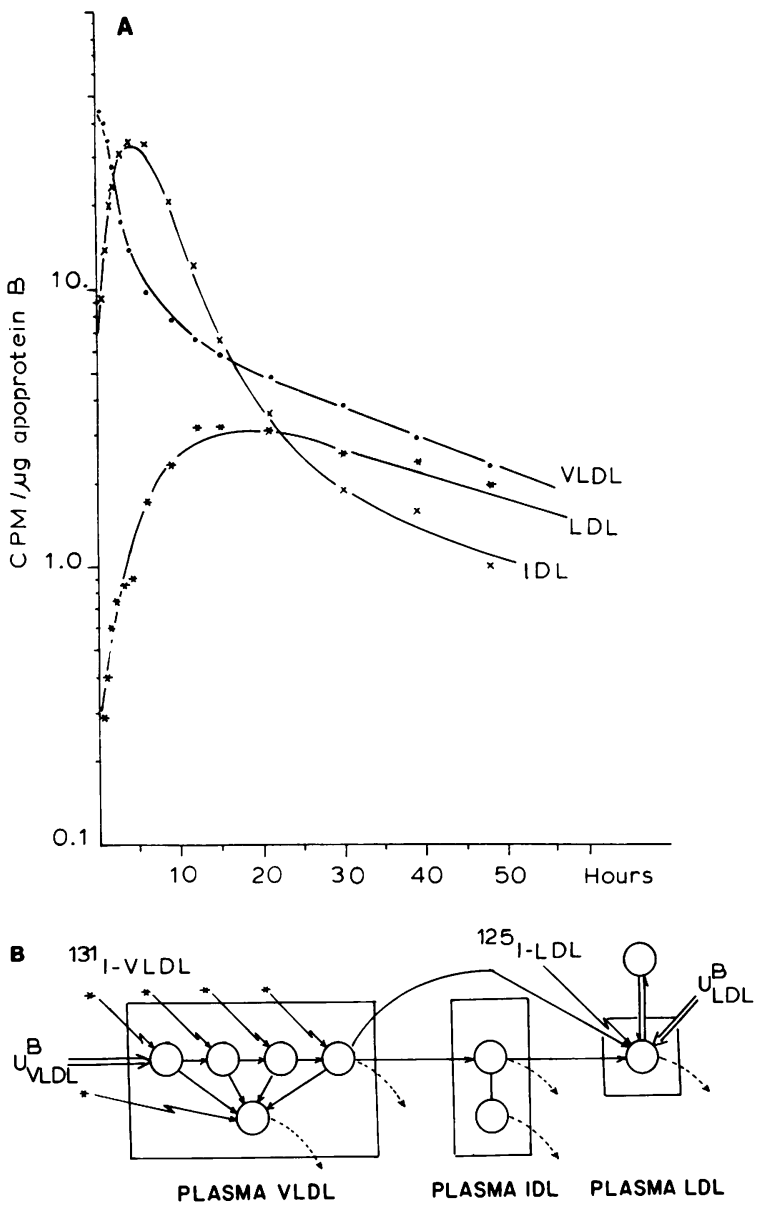

Figure $2 A$. Plasma VLDL, IDL, and LDL apo B specific activity (SA) curves after intravenous injection of radiolabeled VLDL. Several characteristics of these curves are of particular note. The VLDL curve has a slight initial flattening before the biexponential decay. The peak of the IDL apo B SA curve occurs after this curve has crossed the VLDL apo B SA curve. The area under the IDL apo B SA curve was larger than that under the VLDL apo SA curve in all studies. The relationship of the LDL apo B SA curve to those of VLDL and IDL, indicates a complex precursor-product relationship. (B) Compartmental model describing the kinetics of apo B in VLDL, IDL, and LDL in studies where radiolabeled VLDL and LDL are injected. The model includes a four-pool cascade of VLDL apo B where nascent VLDL enters only the first pool. Other assumptions of the model include $(a)$ each pool of the cascade contributes material to a single-side pool that has a much slower fractional turnover; $(b)$ apo B in the fourth pool of the cascade may leave plasma directly, undergo conversion to IDL, or undergo conversion directly to LDL; and $(c)$ apo $B$ in the slow component, which accounts for $10 \%$ of the total VLDL apo B flux, is not converted to denser lipoproteins. The model for IDL apo B has a pool that receives input from VLDL and whose apo B may be removed directly from plasma, converted to LDL, or converted to a second IDL pool that has a much slower fractional turnover. Apo B in the latter pool is removed directly from plasma without conversion to LDL. Finally, the LDL model includes an extravascular equilibration pool and a single removal pathway from plasma. In addition, LDL may be directly secreted into plasma.

program developed by Dr. R. Ramakrishnan (41) at Columbia University. This program is similar to the more general Simultaneous Analysis and Modeling (SAAM) program developed by Berman and Weiss (42) in that it estimates the transfer rates among various compartments directly from the experimental data. The multicompartmental model selected to explain the flux of apo B through VLDL to IDL and LDL (Fig. $2 \mathrm{~B}$ ) includes a four-pool cascade to describe the heterogeneity in the kinetics of apo $B$ in the VLDL density range. Our model differs from an earlier cascade model (2) in that the fractional catabolic rates of apo B in each VLDL subpopulation can vary proportionately at each stage of the cascade. This modification was necessary to explain the variability observed in the specific activity curves. The theoretical basis of our model and its validation are presented in detail elsewhere (Le, N.-A., H. N. Ginsberg, R. Ramakrishnan, R. B. Dell, and W. V. Brown. Metabolic heterogeneity in very low density lipoproteins. Manuscript submitted for publication). Equilibration of the labeled plasma LDL apo B (derived from plasma VLDL) with the extravascular pool of unlabeled LDL apo B was defined in each study by the independent tracer injection of ${ }^{125} \mathrm{I}-\mathrm{LDL}$ using the model suggested by Langer et al. (8). The contribution of a direct source of newly secreted unlabeled apo B in LDL was estimated from the observed dilution of the LDL apo B SA relative to that in VLDL and IDL that could not be accounted for by the extravascular pool.

Statistical analyses of the data were carried out with the paired $t$ test and Wilcoxon signed-rank test. VLDL triglyceride levels presented are the mean of 18 blood samples obtained during the 48-h turnover period. The VLDL and LDL apo B concentrations and the levels of LDL cholesterol presented are the means of six samples obtained during the 48-h turnover period. The fractional standard deviations of all mean concentrations presented were $<15 \%$.

\section{Results $^{2}$}

All subjects lost weight before their repeat studies (Table I). For the group, the mean $( \pm S D)$ percent ideal body weights were $132 \pm 17.9$ at base line and $119 \pm 15.9$ after weight reduction, $P<0.05$. Table II presents the plasma VLDL triglyceride and apo $B$ levels and the LDL cholesterol and apo B concentrations in the subjects during the base-line and post-weight reduction study periods. While they were consuming the baseline diet, both VLDL triglyceride and apo B concentrations were elevated in all of the subjects compared with normals that we have previously studied (43). There was a wide range of values present for both variables. Compared to base line, weight loss resulted in reductions in both VLDL triglyceride $(486.0 \pm 364.1$ vs. $191.3 \pm 65.4 \mathrm{mg} / \mathrm{dl}, P<0.05)$ and VLDL apo B levels $(32.2 \pm 12.0$ vs. $14.8 \pm 6.8 \mathrm{mg} / \mathrm{dl}, P<0.05)$, although most individuals' concentrations were still elevated (Table II). The proportional reductions in triglyceride and apo B were, in general, similar.

The rate of production of VLDL triglyceride ranged from 17.7 to $119.7 \mathrm{mg} / \mathrm{kg}$ per $\mathrm{h}$ in the subjects during their baseline studies (Fig. 3). The mean value for the group $(56.6 \pm 39.0$ $\mathrm{mg} / \mathrm{kg}$ per $\mathrm{h}$ ) was markedly elevated compared with production rates for VLDL triglyceride reported for normal subjects in our laboratory (43). Production rates diminished in all the subjects restudied after weight loss (mean, $28.6 \pm 23.1 \mathrm{mg} / \mathrm{kg}$ per $\mathrm{h}$ ) and this reduction was significant; $P<0.05$. However,

2. The individual kinetic data for all studies is available. An appendix has been deposited with the National Auxiliary Publications Service (NAPS). This information may be ordered from ASIS/NAPS, Microfiche Publications, P.O. Box 3513, Grand Central Station, New York 10017. Remit in advance, in U.S. funds, $\$ 4.00$ for microfiche copy, or for photocopy, $\$ 7.75$ up to 20 pages plus $30 \uparrow$ for additional pages. Outside the U.S. and Canada add postage of $\$ 3.00$ for photocopy and $\$ 1.00$ for microfiche. Checks should be made payable to Microfiche Publications. 
Table II. Effect of Weight Reduction on Very Low and Low Density Lipoprotein Levels

\begin{tabular}{|c|c|c|c|c|c|c|c|c|}
\hline \multirow[b]{2}{*}{ Subject } & \multicolumn{2}{|l|}{ VLDL-TG* } & \multicolumn{2}{|l|}{ VLDL apo B } & \multicolumn{2}{|l|}{ LDL-C $\ddagger$} & \multicolumn{2}{|l|}{ LDL apo B } \\
\hline & Base line & $\begin{array}{l}\text { Post- } \\
\text { reduction }\end{array}$ & Base line & $\begin{array}{l}\text { Post- } \\
\text { reduction }\end{array}$ & Base line & $\begin{array}{l}\text { Post- } \\
\text { reduction }\end{array}$ & Base line & $\begin{array}{l}\text { Post- } \\
\text { reduction }\end{array}$ \\
\hline & \multicolumn{2}{|l|}{$\mathrm{mg} / \mathrm{dl}$} & \multicolumn{2}{|l|}{$\mathrm{mg} / \mathrm{dl}$} & \multicolumn{2}{|l|}{$\mathrm{mg} / \mathrm{dl}$} & \multicolumn{2}{|l|}{$\mathrm{mg} / \mathrm{dl}$} \\
\hline 1 & 346.9 & 245.8 & 26.0 & 24.6 & 67.0 & 63.0 & 50.0 & 57.5 \\
\hline 2 & $1,089.2$ & 228.5 & 50.7 & 19.8 & 54.6 & 101.0 & 55.1 & 70.1 \\
\hline 3 & 272.5 & 176.8 & 35.6 & 16.1 & 75.0 & 94.3 & 71.5 & 88.4 \\
\hline 4 & 130.6 & 80.0 & 21.1 & 6.1 & 78.4 & 110.1 & 74.9 & 77.3 \\
\hline 5 & 764.5 & 252.0 & 40.0 & 12.3 & 44.8 & 45.6 & 46.8 & 48.6 \\
\hline 6 & 312.3 & 164.5 & 20.0 & 9.6 & 64.3 & 94.5 & 51.8 & 75.0 \\
\hline \multirow[t]{2}{*}{ Mean \pm SD } & $486.0 \pm 364.0$ & $191.3 \pm 65.4$ & $32.2 \pm 12.0$ & $14.8 \pm 6.8$ & $64.0 \pm 12.6$ & $84.8 \pm 24.9$ & $58.4 \pm 11.9$ & $69.5 \pm 14.3$ \\
\hline & \multicolumn{2}{|c|}{$P<0.05$} & \multicolumn{2}{|c|}{$P<0.05$} & \multicolumn{2}{|c|}{$P<0.05$} & \multicolumn{2}{|c|}{$P<0.05$} \\
\hline
\end{tabular}

* VLDL-TG, very low density lipoprotein triglyceride. ‡LDL-C, low density lipoprotein cholesterol.

only subject no. 4 had a normal production rate at that time. This same individual was the only one to attain a normal VLDL triglyceride concentration post-weight reduction. There was a wide range of values for the FCR for VLDL triglyceride in the group during the base-line period (Table III). After weight loss, the FCR increased in four subjects and decreased in two subjects. There was no change in the mean FCR for the group overall after weight reduction $(0.34 \pm 0.23$ vs. $0.38 \pm 0.29 \mathrm{~h}^{-1}$ ). The mean FCR for VLDL triglyceride in the study patients during either study period was not different from that which we have reported for normals (43).

VLDL apo B production ranged from 19.7 to 139.7 $\mathrm{mg} / \mathrm{kg}$ per $\mathrm{d}$ in the subjects during base line (Fig. 4). Again, the mean for the group $(47.9 \pm 41.4 \mathrm{mg} / \mathrm{kg}$ per $\mathrm{d})$ was considerably higher than the value previously reported by our group for normal individuals (43). When subjects were studied after weight loss, there was a marked reduction in the mean rate of VLDL apo B secretion for the group $(19.0 \pm 14.1 \mathrm{mg} / \mathrm{kg}$ per day, $P<0.05$ ). Four of the six subjects had normal production rates for VLDL apo $B$ after weight loss. A wide range of fractional catabolic rates for VLDL apo B (Table III) was present in the study group and the rates were reduced in five of the six subjects compared with our previously reported controls (43). After weight loss, as with the fractional catabolic

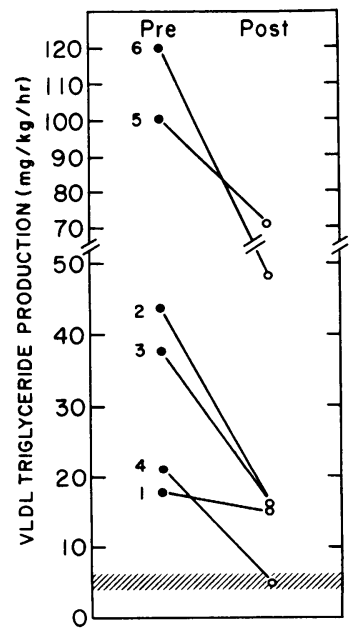

Figure 3. VLDL triglyceride production rates derived from injection of $\left[2-{ }^{3} \mathrm{H}\right] \mathrm{glycerol}$ (see Methods and Figs. $1 A$ and $(B)$. The mean production rate was markedly elevated at base line $(56.6 \pm 39.0 \mathrm{mg} / \mathrm{kg}$ per $\mathrm{h})$. Production of VLDL triglyceride was reduced by weight loss in all subjects and the mean rate decreased signifcantly to $28.6 \pm 23.1 \mathrm{mg} / \mathrm{kg}$ per h. This decrease was significant for the group as a whole $(P<0.05)$. The hatched area represents the mean \pm SEM for five normal subjects studied in our laboratory. rates for VLDL triglyceride, there were variable changes in these rates for VLDL apo B with no significant trend observed.

In association with the elevated plasma levels and increased turnover of VLDL, the hypertriglyceridemic subjects had lownormal or reduced plasma levels of LDL cholesterol and LDL apo B (43) (Table II). After weight loss, subjects demonstrated, in general, elevations in their plasma LDL cholesterol and apo B levels. Mean plasma LDL cholesterol was $64.0 \pm 12.6 \mathrm{mg} / \mathrm{dl}$ during base line and $84.8 \pm 24.9 \mathrm{mg} / \mathrm{dl}$ after weight loss, $P<0.05$. Mean plasma $\mathrm{LDL}$ apo $\mathrm{B}$ concentrations were $58.4 \pm 11.9 \mathrm{mg} / \mathrm{dl}$ and $69.5 \pm 14.3 \mathrm{mg} / \mathrm{dl}$ during the same two study periods. The increase in LDL apo B was also significant; $P<0.05$.

Fig. 5 presents the rates of production of $\mathrm{LDL}$ apo $B$ associated with the concentrations of LDL cholesterol and apo B described above. These estimates are derived from the LDL

Table III. Effect of Weight Reduction on Very Low Density Lipoprotein Catabolism

\begin{tabular}{|c|c|c|c|c|}
\hline \multirow[b]{2}{*}{ Subject } & \multicolumn{2}{|c|}{ Triglyceride-FCR* } & \multicolumn{2}{|l|}{ Apo B-FCR $\ddagger$} \\
\hline & Base line & $\begin{array}{l}\text { Post- } \\
\text { reduction }\end{array}$ & Base line & $\begin{array}{l}\text { Post- } \\
\text { reduction }\end{array}$ \\
\hline & $\%$ & $\%$ & $\%$ & $\%$ \\
\hline 1 & $0.11 \pm 23.1$ & $0.16 \pm 21.7$ & $2.52 \pm 9.8$ & $2.38 \pm 27.8$ \\
\hline 2 & $0.09 \pm 17.8$ & $0.19 \pm 20.6$ & $0.86 \pm 10.5$ & $0.98 \pm 12.9$ \\
\hline 3 & $0.35 \pm 17.5$ & $0.20 \pm 30.1$ & $2.26 \pm 27.1$ & $1.66 \pm 34.8$ \\
\hline 4 & $0.35 \pm 15.3$ & $0.17 \pm 17.6$ & $3.58 \pm 26.6$ & $2.69 \pm 36.1$ \\
\hline 5 & $0.35 \pm 14.3$ & $0.64 \pm 15.4$ & $1.58 \pm 18.3$ & $2.21 \pm 24.3$ \\
\hline \multirow[t]{2}{*}{6} & $0.79 \pm 12.7$ & $0.91 \pm 15.5$ & $17.52 \pm 19.2$ & $10.94 \pm 25.3$ \\
\hline & \multicolumn{2}{|c|}{ NS } & \multicolumn{2}{|c|}{ NS } \\
\hline $\begin{array}{l}\text { Normals } \\
(n=5)\end{array}$ & $\begin{array}{l}0.33 \pm 0.07 \\
\text { (Mean SD) }\end{array}$ & & $\begin{array}{l}6.24 \pm 3.1 \\
\text { (Mean SD) }\end{array}$ & \\
\hline
\end{tabular}

* Data are presented as FCR in pools per hour \pm the fractional SD (in percent). The fractional SD was estimated from the fitting program for the entire VLDL triglyceride curve.

¥ Data are presented as FCR in pools per day \pm the fractional SD (in percent). The overall FCR for VLDL apo B is derived from the fractional turnover rate of the cascade process and the fractional turnover rate of the slow component. $\sim 90 \%$ of the overall metabolism of VLDL apo B is accounted for by the cascade process. The fractional SD of the latter rate is presented above as a measure of the confidence of this parameter as estimated by the computer program. 


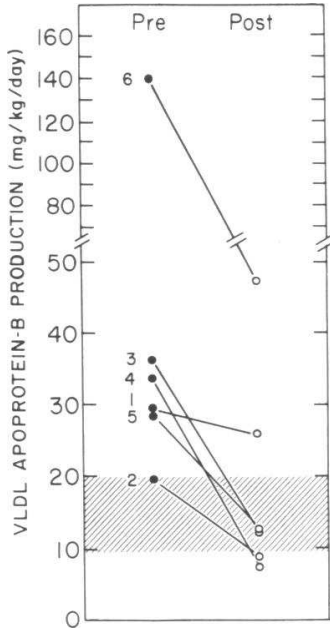

Figure 4. VLDL apo B production rates derived from injection of radiolabeled VLDL (see Methods and Figs. $2 A$ and $2 B$ ). Similar to VLDL triglyceride, the mean production rate for VLDL apo B was markedly increased during the base-line studies $(47.9 \pm 41.4 \mathrm{mg} / \mathrm{kg}$ per d). Production of VLDL apo B was reduced in all subjects after weight reduction with the mean rate significantly reduced $(19.0 \pm 14.1 \mathrm{mg} / \mathrm{kg}$ per d). This decrease was significant for the group as a whole $(P<0.05)$. The hatched area represents the mean \pm SEM for five normal subjects studied in our laboratory.

decay data after a separate injection of ${ }^{125} \mathrm{I}-\mathrm{LDL}$. Two important conclusions can be drawn from these data. First, in the baseline state, there was a wide range of production rates of LDL apo B but all individuals had normal or elevated levels of production (mean, $17.4 \pm 7.2 \mathrm{mg} / \mathrm{kg}$ per d) compared with our previously reported controls (43). Thus, low plasma LDL cholesterol and apo B concentrations in these hypertriglyceridemic subjects were not associated with reduced rates of LDL production. Second, after weight loss, when plasma LDL levels rose, the mean $L D L$ apo $B$ production rate was $14.4 \pm 2.8$ $\mathrm{mg} / \mathrm{kg}$ per $\mathrm{d}$, which was not significantly different from the mean production rate during base line. LDL production fell significantly in two subjects but was essentially unchanged in the other four. In any event, it is clear that the uniform increases in plasma LDL concentrations were not the result of increased LDL production.

The mean fractional catabolic rate for LDL apo B during the base-line period was $0.68 \pm 0.29 \mathrm{~d}^{-1}$. This was increased compared with our previously reported normals (43). The LDL apo B FCR fell in five of the six patients after weight loss (Fig. 6). The mean for the group at that time was $0.48 \pm 0.11 \mathrm{~d}^{-1}$. This reduction in FCR after weight loss was significant $(P<0.05)$ and was associated with the increases in plasma LDL levels described above.

To determine the relationship between the changes observed in the turnover of VLDL apo B and those observed in the turnover of LDL apo B after weight loss, we used multicom-

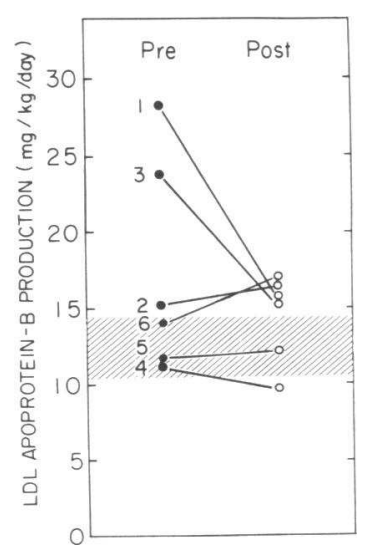

Figure 5. Production rates of LDL apo B derived from direct injection of radiolabeled LDL (see Methods and Fig. $2 \mathrm{~B}$ ). During the base-line period, the mean $\mathrm{LDL}$ apo $B$ production rate was elevated $(17.4 \pm 7.2 \mathrm{mg} / \mathrm{kg}$ per day). Production of LDL apo B was decreased in three subjects and minimally increased in three subjects after weight reduction and the mean rate fell slightly to $14.4 \pm 2.8 \mathrm{mg} / \mathrm{kg}$ per day. These changes were not significant for the group as a whole. The hatched area represents the mean \pm SEM for five normal subjects studied in our laboratory.

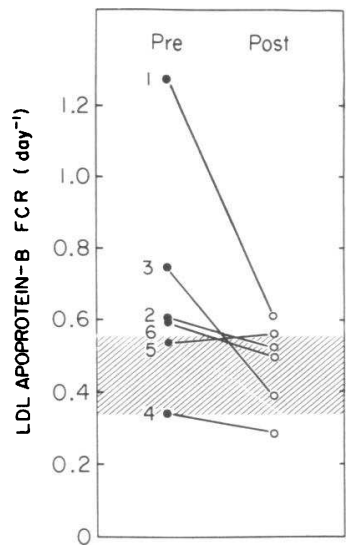

Figure 6. Fractional catabolic rates of LDL apo $B$ before and after weight loss. These data were derived from the separate injection of radiolabeled LDL. During base line, the mean fractional catabolic rate was elevated $\left(0.68 \pm 0.29 \mathrm{~d}^{-1}\right)$. The fractional catabolic rates fell in five of six subjects after weight loss and the mean at that time was $0.48 \pm 0.11 \mathrm{~d}^{-1}$. This fall was significant for the group as a whole ( $P$ $<0.05$ ). The hatched area represents the mean \pm SEM for five normal subjects studied in our laboratory.

partmental analysis to identify the sources of LDL production during each study. The results of this analysis, depicted in Fig. 7 , demonstrated two sources of LDL apo B production in these subjects. The rate of production of LDL apo $B$ generated by the catabolism of VLDL apo B (hatched areas) was sufficient to account for the total rate of LDL apo B production in only one of the subjects during base line (No. 3). Thus, there seemed to be direct entry of LDL apo B into plasma (open area), during all but one of the base-line studies. After weight loss, while the absolute flux of LDL apo B generated by the catabolism of VLDL apo B fell in five of six subjects, direct secretion of LDL apo B increased in all six individuals (Table IV). These changes resulted in a reversal of the proportions of LDL apo B derived from VLDL and from direct production after weight reduction (Fig. 7). In the six subjects, $73.3 \pm 17.2 \%$ of LDL was derived from VLDL and $26.7 \pm 18.3 \%$ entered plasma directly during the base-line period. These values were $46.8 \pm 17.6 \%$ and $53.2 \pm 19.8 \%$, respectively, after weight loss. These changes were significant; $P<0.05$. It should also be noted that although the percentage of VLDL apo B flux that was converted to LDL, apo B increased in five of the six individuals post-weight reduction compared with base line, the mean increase was not significant $(37.9 \pm 21.1$ vs. $47.4 \pm 24.7 \%$, NS). Furthermore, as noted above, the absolute amounts of apo B converted to LDL from VLDL fell in 5 of 6 subjects.

Physico-chemical characterization of VLDL and LDL was

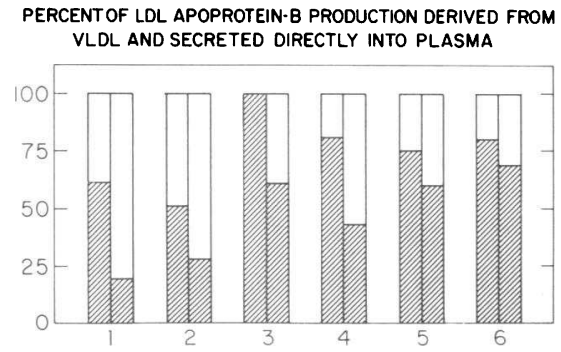

Figure 7. Percent of total LDL apo B production derived from either VLDL apo B (hatched area) or directly secreted LDL apo B (open area) in each subject pre-weight reduction (left bar of each pair) and post-weight reduction (right bar of each pair). All subjects, except no. 3 pre-weight loss, had LDL apo B that was secreted directly into plasma. After weight loss, the proportion of LDL derived from directly secreted particles increased in all subjects. These changes were significant for the group as a whole $(P<0.05)$. 
Table IV. Sources of Low Density Lipoprotein Apo B

\begin{tabular}{|c|c|c|c|c|}
\hline \multirow[b]{2}{*}{ Subject } & \multicolumn{2}{|c|}{ VLDL conversion } & \multicolumn{2}{|c|}{ Direct LDL production } \\
\hline & Base line & $\begin{array}{l}\text { Post- } \\
\text { reduction }\end{array}$ & Base line & $\begin{array}{l}\text { Post- } \\
\text { reduction }\end{array}$ \\
\hline & $\begin{array}{l}m g / k g \text { per } \\
\text { day }\end{array}$ & $\begin{array}{l}m g / k g ~ p e r \\
\text { day }\end{array}$ & $\begin{array}{l}\mathrm{mg} / \mathrm{kg} \text { per } \\
\text { day }\end{array}$ & $\begin{array}{l}\mathrm{mg} / \mathrm{kg} \text { per } \\
\text { day }\end{array}$ \\
\hline 1 & 16.9 & 3.2 & 11.2 & 12.5 \\
\hline 2 & 7.9 & 4.6 & 7.2 & 11.7 \\
\hline 3 & 23.7 & 9.4 & 0 & 6.1 \\
\hline 4 & 9.1 & 4.0 & 2.2 & 5.5 \\
\hline 5 & 8.4 & 7.7 & 3.0 & 4.5 \\
\hline 6 & 11.1 & 11.4 & 2.9 & 5.6 \\
\hline \multirow[t]{2}{*}{ Mean \pm SD } & $12.85 \pm 6.3$ & $6.72 \pm 3.3$ & $4.42 \pm 4.1$ & $7.65 \pm 3.5$ \\
\hline & \multicolumn{2}{|c|}{$P<0.05$} & \multicolumn{2}{|c|}{$P<0.05$} \\
\hline
\end{tabular}

performed during each study period. The ratio of triglyceride to apo B in VLDL, an indication of particle size, varied widely during the base-line studies with a range of values from 6.3 to 21.5. After weight loss these ratios were not altered in any systematic fashion. Subjects 2 and 5 , with the highest ratios, had a large reduction and no change, respectively, in their ratios. Subjects 3 and 4 , with the lowest ratios, both had increases in this variable after weight loss. Finally, comparison of the VLDL triglyceride to apo $B$ ratios with the various kinetic parameters determined during base line and after weight loss did not reveal any pattern. During the base-line state, LDL was cholesterol-poor and relatively triglyceride-rich (data not shown). After weight reduction the LDL increased its cholesterol content in four of the six subjects (Table II). Weight reduction was associated with a marked elevation of the mean cholesterol/protein ratio. The mean ratio was $1.00 \pm 0.18$ during base line and increased to $1.25 \pm 0.27(P$ $<0.05$ ) after weight reduction. It should be noted that subject 1 , who had a near-normal cholesterol/protein ratio during base line, had a large reduction in this ratio after weight loss. However, this heterogeneity was not associated with any other systematic differences in his overall pattern of apo B metabolism compared with the rest of the group.

The electrophoretic mobility of LDL in agarose was normal in these subjects and was unaffected by weight loss. Polyacrylamide gel electrophoresis was carried out in subjects 1, 4, 5, and 6 to determine if intestinal apo B was present in these lipoproteins. Fasting VLDL from these subjects contained a trace amount of material migrating at a molecular weight of $\sim 220,000$. None of this material was present in their LDL samples, while each showed a single band at $\sim 330,000$ mol wt.

\section{Discussion}

It has been long observed that in spite of increased rates of VLDL production (2-4, 13-17), many subjects with hypertriglyceridemia have reduced plasma concentrations of LDL (18, 19). It has also been demonstrated, by several investigators, that plasma VLDL and LDL concentrations change in a reciprocal fashion as a result of physiologic $(20,21,23)$ and pharmacologic $(21,22)$ perturbations. Because plasma VLDL is the precursor of plasma LDL, it has been assumed that the degree of conversion of VLDL to LDL must be the key component in the regulation of plasma LDL concentration. Thus, reduced conversion of VLDL to LDL in hypertriglyceridemic subjects could result in low LDL levels, while an increase in that conversion concomitant with reduced VLDL levels would result in higher LDL concentrations. However, alternative explanations for the reciprocal relationship between VLDL and LDL exist. For example, the cholesterol content of LDL may be reduced in hypertriglyceridemic subjects (21) and the fractional catabolic rate for LDL apo $B$ may be increased $(13,16,25)$. Finally, generation of LDL from sources other than VLDL, i.e., direct secretion of LDL $(6,14,24,44)$, might also regulate steady-state plasma LDL concentrations. We have, therefore, used weight loss to investigate the regulation of plasma LDL concentrations in hypertriglyceridemic subjects at two different levels of plasma VLDL.

The results of these studies demonstrate the complexity of the regulatory system controlling the plasma concentration of LDL cholesterol. Although some heterogeneity did exist in this group of subjects who phenotypically had Type IV hyperlipoproteinemia, several general conclusions can be drawn relating the plasma concentrations of VLDL and LDL and the metabolism of those lipoproteins during the base-line state. First, in accord with reports from several laboratories (2-4, 13-17) the elevated plasma VLDL apo B and triglyceride levels present were associated with elevated rates of secretion of VLDL particles in all six subjects. Second, although $<40 \%$ of the VLDL particles secreted under base-line conditions in our subjects were converted to $\operatorname{LDL}(3,4,6)$, the production rates of LDL apo B were actually normal or elevated. These rates resulted, in part, from the high VLDL turnover rates. Thus, even though a small fraction of VLDL particles was converted to LDL, the absolute rate of flux of particles from VLDL to LDL was normal or high. The total flux of apo B into LDL was increased even further by direct entry of particles into plasma in the LDL density range in all but one of the six subjects during base line. Finally, in spite of normal or high input rates of $\mathrm{LDL}$ apo $B$, the steady-state plasma concentrations of LDL cholesterol and apo B were maintained at reduced or low-normal levels by both increased fractional catabolic rates of LDL apo B and a reduced cholesterol content of each LDL particle. Both of these abnormalities have been noted to occur in subjects with hypertriglyceridemia $(11,13$, $14,24,25$ ).

The alteration in lipoprotein metabolism associated with weight loss further illustrated the complex manner in which several metabolic variables interacted to regulate LDL cholesterol concentrations. First, the fall in VLDL levels to new steady-state concentrations after weight loss was associated with a fall in the secretion of VLDL into plasma in all six subjects. Although the percent conversion of VLDL apo B to LDL apo $B$ increased in five of the six subjects, the fall in absolute VLDL apo B flux resulted in a reduction in the absolute amount of apo B entering the LDL density range from VLDL in five of the six individuals. However, while LDL production from VLDL was reduced, total LDL apo B production fell in only two of the six subjects because the flux of apo $B$ directly into the LDL density range increased in all. In fact, in three subjects the predominant source of apo B in LDL after weight loss was independent of VLDL catabolism. Finally, in parallel with the shift in the source of LDL apo B, two other factors critical to the regulation of the plasma LDL 
cholesterol level were also affected by weight loss. The FCR of LDL decreased in five of six subjects, and the ratio of cholesterol to protein in LDL increased in four of the six individuals.

One of the striking findings in our study was the demonstration of "direct" secretion of LDL apo B into plasma. This result was based on the multicompartmental analysis of our data using our model. The theoretical basis for and validation of this model will be presented elsewhere. It should be pointed out, however, that input of nonradiolabeled ("cold") material into plasma within the LDL density range was necessitated by dilution of the ${ }^{131} \mathrm{I}$-apo $B$ specific activity in LDL relative to that observed in VLDL and IDL after the injection of ${ }^{131} \mathrm{I}-$ VLDL. Only entry of nonradiolabeled apo B directly into LDL could account for such a dilution of specific activity. Our kinetic analysis did not require direct entry of some IDL apo $B$ in addition to direct secretion of LDL, but we could not rule out that possibility. Direct secretion of particles more dense than VLDL have been most clearly demonstrated in studies of individuals with familial hypercholesterolemia (6) and dysbetalipoproteinemia (44). However, Janus et al. (6), using deconvolution analysis, found direct LDL production in some subjects with hypertriglyceridemia, while Fisher et al. (14), using $\left[{ }^{3} \mathrm{H}\right]$ leucine as an endogenous tracer and a multicompartmental model similar to ours, observed direct secretion of apo B containing lipoproteins into the IDL and LDL range in several subjects with severe hypertriglyceridemia. Eaton et al. (24) reported similar findings in studies using $\left[{ }^{35}\right.$ S]methionine. More recently, Kesaniemi et al. (45), in a preliminary report, suggested that direct secretion of LDL into plasma occurs in subjects with normal and mildly elevated plasma LDL cholesterol levels.

Our results, together with those of other investigators cited above, also indicate that the secretion of apo B across a wide range of lipoprotein densities may be more common than previously appreciated. The relationship between this capacity to alter the density of the lipoprotein particles secreted, and the changes in LDL composition and catabolism we have observed is not clear, but certainly deserves attention. However, the reciprocal relationship demonstrated for the rates of secretion into plasma of VLDL and LDL apo B in the pre- and post-weight reduction periods in this study suggests that the concomitant secretion of triglyceride (and possibly cholesterol) may play a significant role in determining the density of the secreted lipoprotein particles. A similar proposal has been made by Nestel et al. (46) to explain the increased secretion of $S_{\mathrm{f}}$ 12-60 particles in subjects fed high cholesterol diets. This mechanism may also be crucial in determining the phenotypic expression of the combined hyperlipoproteinemia genotype(s) in which elevated production of apo B may be the primary defect (16).

The results of these kinetic studies, carried out using weight loss to allow quantitation of apo B flux at different plasma concentrations of VLDL and LDL, indicate that plasma LDL levels in hypertriglyceridemic subjects are regulated, to a large degree, by the fractional catabolic rate and the cholesterol content of that lipoprotein. An increased plasma VLDL pool can act as a "sink" for cholesterol esters transferred from LDL $(47,48)$, and enrichment of LDL with cholesterol has been observed after weight loss, associated with reductions in VLDL levels (21). Thus, changes in steady-state plasma lipoprotein pools can contribute significantly to the alterations in LDL cholesterol concentrations observed. But this mechanism cannot explain the concomitant increase in LDL apo B demonstrated. The latter change was most likely the direct consequence of the fall in the FCR of LDL apo B that occurred after weight loss. The elevated LDL apo B FCR present during base line was associated with a high rate of flux of VLDL into the LDL density range. This high flux rate could have resulted in small increases in the concentrations of non-apo B apolipoproteins, such as apo E, in LDL. Such compositional changes could, in turn, alter the fractional catabolism of that LDL (49). After weight loss, when the flux of apo B from VLDL was significantly reduced, apolipoprotein composition may have been more uniform. We previously demonstrated a marked reduction in the FCR of LDL apo B in a subject whose VLDL production was dramatically reduced after posta-caval shunt (50). On the other hand, directly secreted LDL may have a much slower fractional catabolic rate than LDL derived from VLDL. The overall FCR for LDL apo B would reflect that relative amounts of LDL derived from VLDL and non-VLDL sources.

Finally, these studies point out the necessity of obtaining data related to the rate of lipoprotein transport before interpreting the clinical relevance of changes in static measurements. Thus, the rise in LDL cholesterol levels that occurs when VLDL triglyceride concentrations are reduced by various perturbations might lead an observer to question the clinical efficacy of such interventions. However, several investigators have suggested that the flux of LDL apo $B$ may be an important risk factor for atherosclerosis $(11,51)$, and LDL flux was either reduced or unchanged in our subjects after weight loss. Furthermore, total apo B turnover (VLDL plus LDL) was significantly reduced by weight reduction. Thus, the rise in plasma LDL levels after weight reduction may belie an improvement in lipoprotein metabolism that actually occurs. While the present studies do not provide data directly relevant to this issue of concentration versus flux, they make it clear that assessment of the clinical efficacy of measures that alter static plasma lipid concentrations may require data describing the changes in lipoprotein transport resulting from those interventions.

\section{Acknowledgments}

The authors wish to thank Dr. W. V. Brown for his continued support; Dr. R. Dell and Dr. R. Ramakrishnan of the Biomathematics Core, Special Center of Research, Arteriosclerosis (HL 07343) at Columbia University College of Physicians and Surgeons, for their help in the development of our compartmental model and for the use of their computer facilities at Columbia University; C. Mays, C. Martin, J. Lee, M. Grosz, T. Han, and R. Veiss, for their excellent technical assistance; M. Kalin and D. Lieberman for their superb dietary care; and the nursing staff of the General Clinical Research Center for their outstanding care of our patients. Finally, special thanks to M. Shiffer and $\mathbf{M}$. Harris for preparation of this manuscript.

This work was supported by the following grants: HL23077, HL25752, HL27170, and HL00949; RR-71, Division of Research Resource, General Clinical Research Centers.

\section{References}

1. Bilheimer, D. W., S. Eisenberg, and R. I. Levy. 1972. The metabolism of very low density lipoprotein proteins. I. Preliminary in vitro and in vivo observation. Biochim. Biophys. Acta. 260:212-221. 
2. Berman, M., M. Hall, R. I. Levy, S. Eisenberg, D. W. Bilheimer, R. D. Phair, and R. H. Goebel. 1978. Metabolism of apo B and apo $\mathrm{C}$ lipoproteins in man: kinetic studies in normal and hyperlipoproteinemic subjects. J. Lipid Res. 19:38-55.

3. Reardon, M. F., N. H. Fidge, and P. J. Nestel: 1978. Catabolism of very low density lipoprotein B apoprotein in man. J. Clin. Invest. 61:850-860.

4. Ginsberg, H. N., N.-A. Le, J. Melish, D. Steinberg, and W. V. Brown: 1981. Effect of a high carbohydrate diet on apoprotein-B metabolism in man. Metab. Clin. Exp. 30:347-353.

5. Sigurdsson, G., A. Nicoll, and B. Lewis. 1975. Conversion of very low density lipoprotein to low density lipoprotein. J. Clin. Invest. 56:1481-1490.

6. Janus, E. D., A. Nicoll, R. Wootton, P. R. Turner, P. J. Magill, and B. Lewis. 1980. Quantitative studies of very low density lipoprotein: conversion to low density lipoprotein in normal controls and primary hyperlipidemic states and the role of direct secretion of low density lipoprotein in heterozygous familial hýpercholesterolemia. Eur. J. Clin. Inves̀t. 10:149-159.

7. Goldstein, J. L., and M. S. Brown. 1982. Lipoprotein receptors: genetic defense against atherosclerosis. Clin. Res. 30:417-426.

8. Langer, T., W. Strober, and R. I. Levy. 1972. The metabolism of low density lipoprotein in familial type II hyperlipoproteinemia. $J$. Clin. Invest. 51:1528-1536.

9. Shepherd, J., S. Bicker, A. R. Lorimer, and C. J. Packard. 1979. Receptor mediated low density lipoprotein metabolism in man. $J$. Lipid Res. 20:999.-1006.

10. Pittman, R. C., T. E. Carew, A. D. Attee, J. L. Witztum, Y. Watanabe, and D. Steinberg. 1982. Receptor dependent and receptor independent degradation of low density lipoprotein in normal rabbits and in receptor deficient mutant rabbits. J. Biol. Chem. 257:79948000 .

11. Kesaniemi, Y. A., and S. M. Grundy. 1982: Significance of low density lipoprotein production in the regulation of plasma cholesterol level in man. J. Clin. Invest. 70:13-22.

12. Simons, L. A., D. Reichl, N. B. Myant, and M. Mancini. 1975. The metabolism of the apoprotein of plasma low density lipoprotein in familial hyperbetalipoproteinemia in the homozygous form. Atherosclerosis. 21:283-298.

13. Janus, E. D., A: M. Nicoll, P. R. Turner; P. Magill, and B. Lewis. 1980. Kinetic bases of the primary hyperlipidaemias: studies of apolipoprotein B turnover in genetically defined subjects. Eur. J. Clin. Invest. 10:161-172.

14. Fisher, W. R., L. A. Zech, P. Bardalaye, G. Warmke, and M. Berman. 1980. The metabolism of apolipoprotein B in subjects with hypertriglyceridemia and polydisperse LDL. J. Lipid Res. 21:760-774.

15. Packard, C. J., J. Shepherd, S. Joerns, A. M. Gotto, and O. D. Taunton. 1980. Apolipoprotein B metabolism in normal, type IV and type V hyperlipoproteinemic subjects. Metab. Clin. Exp. 29:213-221.

16. Chait, A., J. J. Albers, and J. D. Brunzell. 1980. Very low density lipoprotein overproduction in genetic forms of hypertriglyceridaemia. Eur. J. Clin. Invest. 10:17-22.

17. Kissebah, A. H., S. Alfarsi, and P. W. Adams. 1981. Integrated regulation of very low density lipoprotein triglyceride and apolipoproteinB kinetics in man: normolipidemic subjects, familial hypertriglyceridemia and familial combined hyperlipidemia. Metab. Clin. Exp. 30: 856-868.

18. Fredrickson, D. S., R. I. Levy, and F. T. Lindgren. 1968. A comparison of heritable abnormal lipoprotein patterns as defined by two different techniques. J. Clin. Invest. 47:2446-2457.

19. Phillips, N. R., R. J. Havel, and J. P. Kane. 1981. Levels of interrelationships of serum and lipoprotein cholesterol and triglycerides. Arteriosclerosis. 1:13-24.

20. Havel, R. J., and R. S. Gordon, Jr. 1960. Idiopathic hyperlipidemia. Metabolic studies in an affected family. J. Clin. Invest. 39: 1777-1790.
21. Wilson, D. E., and R. S. Lees. 1972. Metabolic relationship among the plasma lipoproteins. J. Clin. Invest. 51:1051-1057.

22. Strisower, E. H., G. Adamson, and B. Strisower. 1968. Treatment of hyperlipidemias. Am. J. Med. 45:488-501.

23. Melish, J., N.-A. Le, H. Ginsberg, D. Steinberg, and W. V. Brown. 1980. Dissociation of apoprotein B and triglyceride production in very low density lipoproteins. Am. J. Physiol. 239:E354-362.

24. Eaton, R. P., R. C. Allen, and D. S. Schade. 1984. Overproduction of a kinetic subclass of VLDL apo $B$, and direct catabolism of VLDL apo $B$ in human endogenous hypertriglyceridemia: an analytical model solution of tracer data. J. Lipid Res. 24:1291-1303.

25. Sigurdsson, G., A. Nicoll, and B. Lewis. 1976. The metabolism of low density lipoprotein in endogenous hyprtriglyceridemia. Eur. J. Clin. Invest. 6:151-158.

26. Frederickson, D. S., J. L. Goldstein, and M. S. Brown. 1978. The familial hyperlipoproteinemias. In The Metabolic Basis of Inherited Disease. J. B. Stanbury, J. B. Wyngaarden, and D. S. Fredrickson, editors: McGraw-Hill Inc., New York. Fourth ed. 604-655.

27. Heiss, G., I. Tamir, C. E. Davis, H. A. Tyroler, B. M. Rifkind, G: Schorifeld, D. Jacobs, and I. D. Frantz. 1980. Lipoprotein cholesterol distributions in selected North American populations. The Lipid Research Clinics program prevalence study. Circulation. 61:302-315.

28. Grundy, S. M., H. Y. I. Mok, L. Zech, D. Steinberg, and M. Berman. 1979: Transport of very low density lipoprotein triglycerides in varying degrees of obesity and hypertriglyceridemia. J. Clin. Invest. 63:1274-1283.

29. Zech, L. A., S. M. Grundy, D. Steinberg, and M. Berman. 1979. Kinetic model for production and metabolism of very low density lipoprotein triglycerides. J. Clin. Invest. 63:1262-1273.

30. Turner, J. D., N.-A. Le, and W. V. Brown. 1981. Effect of changing dietary fat saturation on low density lipoprotein metabolism in man. Am. J. Physiol. 4:E57-E63.

31. McFarlane, A. S. 1958. Efficient trace labeling of proteins with iodine. Nature (Lond.). 182:153.

32. Le, N.-A., J. S. Melish, B. C. Roach, H. N. Ginsberg, and W. V. Brown. 1978. Direct measurement of apoprotein B specific activity in ${ }^{125}$ I labeled lipoproteins. J. Lipid Res. 19:578-584.

33. Lowry, O. H., N. J. Rosebrough, A. L. Farr, and R. J. Randall. 1951. Protein measurement with the Folin phenol reagent. J. Biol. Chem. 193:265-275.

34. Lipid Research Clinics Program. 1974. Lipid and Lipoprotein Analysis. Manual of Laboratory Operations. Vol. 1. National Institutes of Health; Bethesda, MD, publisher. Department of Health, Education, and Welfare Publication No. 75-628.

35. Finely., P. R., R. B. Schifman, R. J. Williams, and D. R. Lichti. 1978. Cholesterol in high density lipoprotein: use of $\mathrm{Mg} 2+$ /dextran sulfate in its enzymatic measurement. Clin. Chem. 24:931-933.

36. Krishnaiah, K. V., L. F. Walker, J. Borensżtajn, G. Schonfeld, and G. S. Getz. 1980. Apolipoprotein B variant derived from rat intestine. Proc. Natl. Acad. Sci. USA. 77:3806-3810.

37. Noble, R. P. 1968. Electrophoretic separation of plasma lipoproteins in agarose gel. J. Lipid Res. 9:693-700.

38. Curry, M. D., P. Alaupovic, and C. A. Suenram. 1976. Determination of apolipoprotein-A and its constitutive AI and AII polypeptides by separate electroimmunoassay. Clin. Chem. 22:315322.

39. Gibson, J. C., A. Rubinstein, P. R. Bukberg, and W. V. Brown. 1983. Apolipoprotein $\mathrm{E}$ enriched lipoprotein subclasses in normolipidemic subjects. J. Lipid Res. 24:886-898.

40. Le, N.-A., S. M. Grundy, and M. Berman. 1982. A reduced model for very low density lipoprotein triglyceride metabolism. In Lipoprotein Kinetics and Modeling. M. Berman, S. M. Grundy, and R. Howard, Editors. Academic Press, New York. 461-470.

41. Ramakrishnan, R., R. B. Dell, and D. S. Goodman. 1981. On determining the extent of side pool synthesis in a three-pool model for whole body cholesterol kinetics. J. Lipid Res. 22:1174-1180.

42. Berman, M., and M. F. Weiss. 1978. SAAM Manual. Depart- 
ment of Health, Education, and Welfare, Washington, DC. Publication No. (NIH) 78-180.

43. Ginsberg, H., N.-A. Le, C. Mays, J. Gibson, and W. V. Brown. 1981. Lipoprotein metabolism in nonresponders to increased dietary cholesterol. Arteriosclerosis. 1:463-470.

44. Reardon, M. F., M. Poapst, and G. Steiner. 1982. The independent synthesis of intermediate density lipoproteins in type III hyperlipoproteinemia. Metab. Clin. Exp. 31:421-427.

45. Kesaniemi, Y. A., W. F. Beltz, and S. M. Grundy. 1981. Role of direct secretion of low density lipoprotein in causation of primary hypercholesterolemia. Arteriosclerosis. 1:366a. (Abstr.)

46. Nestel, P., N. Tada, and T. Billington. 1982. Changes in very low density lipoproteins with cholesterol loading in man. Metabolism. 31:395-405.

47. Fisher, W. R. 1983. Heterogeneity of plasma low density lipoproteins: manifestations of the physiologic phenomenon in man. Metab. Clin. Exp. 32:283-291.
48. Decklebaum, R. J., S. Eisenberg, Y. Oschry, E. Butbul, I. Sharon, and T. Olivecrona. 1982. Reversible modification of human plasma low density lipoproteins toward triglyceride rich precursors: a mechanism for losing excess cholesteryl esters. J. Biol. Chem. 257: 6509-6517.

49. Mahley, R. W., K. H. Weisgraber, and T. L. Innerarity. 1979. Interaction of plasma lipoproteins containing apolipoproteins $\mathrm{B}$ and $\mathrm{E}$ with heparin and cell surface receptors. Biochim. Biophys. Acta. 575: 81-91.

50. Ginsberg, H., N. Davidson, N.-A. Le, J. Gibson, E. H. Ahrens, Jr., and W. V. Brown. 1982. Marked overproduction of low density lipoprotein apolipoprotein B in a subject with heterozygous familial hypercholesterolemia. Biochim. Biophys. Acta. 7i2:250-257.

51. Brunzell, J. D., A. D. Sniderman, J. J. Albers, and P. O. Kwiterovich, Jr. 1984. Apoproteins B and A-1 and coronary artery disease in humans. Arteriosclerosis. 4:79-83. 